\title{
U.S. States Hit the Hardest by COVID-19 Have Lower Unemployment Risks
}

Sungki Hong, Economist

Devin Werner, Research Associate

T

he number of confirmed cases of COVID-19 in the United States is rapidly increasing. In response, federal and local governments are implementing social distancing measures to curb the spread of the virus. Inevitably, economic activities are being disrupted and workers are losing their jobs-especially those who work in nonessential sectors or cannot work from home. In this essay, we look at whether the states hit the hardest by the outbreak so far tend to have a labor market less likely to suffer job loss due to COVID-19, in order to analyze broadly which areas may face the worst economic impacts from the current crisis. We assess labor market conditions based on the nature of occupations.

\section{An Overview of Outbreaks and Occupational Risk by State}

First, we obtain the latest numbers of reported cases across the 50 states from data compiled by Johns Hopkins University for Wednesday, April 1. We then calculate the fraction of each state's population confirmed to have COVID-19, using population data from the February 2020 Current Population Survey.

\section{States with relatively more} COVID-19 cases - so far-tend to have more workers less likely to lose their jobs.

Panel A of Figure 1 illustrates the state-by-state incidences of confirmed cases. COVID-19 has hit some states harder than others. New York is the clear outlier, with 0.438 percent of the population diagnosed with the virus; New Jersey (0.253 percent), Louisiana (0.142 percent), Massachusetts ( 0.113 percent), and Connecticut (0.101 percent) follow. The least-affected states are West Virginia (0.011 percent), Nevada (0.011 percent), Minnesota (0.012 percent), Kentucky (0.014 percent), and Texas (0.015 percent).
We then assess the fraction of a state's workers likely to be laid off during the COVID-19 pandemic, using Gascon's (2020) methodology. Three factors are considered to evaluate the layoff risk of an occupation:

1. The work is considered essential; for example, doctors, lawyers, and postal workers.

2. The person could complete work via telecommuting; for example, secretaries, designers, college professors, and economists.

3. The worker is likely to be salaried; for example, preschool teachers and librarians.

An occupation is categorized as high risk of unemployment if it does not satisfy any of the above criteria. Such occupations include, but are not limited to, event planners, foresters, childcare workers, roofers, and servers. We then apply this analysis to state-level Occupational Employment Statistics published by the U.S. Bureau of Labor Statistics (BLS), to calculate the fraction of workers in a state working in high-risk occupations.

Panel B of Figure 1 shows clear heterogeneity in layoff risk across states. The percentage of the workforce in highrisk occupations varies by almost 14 percentage points across states. Nevada faces the most risk, with 55.3 percent of its labor force employed in occupations considered at high risk of unemployment, followed by Wyoming (53.9 percent), Indiana (52.5 percent), South Carolina (51.2 percent), and North Dakota (50.8 percent). Conversely, Massachusetts faces the least risk (40.2 percent), followed by Maryland (40.4 percent), Delaware (40.4 percent), New Jersey (41.8 percent), and New York (41.8 percent).

\section{Twin Crises}

We document the medical and economic risks separately above, but we also look at how the percentage of confirmed COVID-19 cases varies with high-risk occupations across states. A state's workforce could better weather the outbreak if more of its workers are in low-risk occupations. Panel A of Figure 2 shows a scatterplot of the two variables. The 
Figure 1

\section{A. Percentages of the Population that Tested Positive for COVID-19}

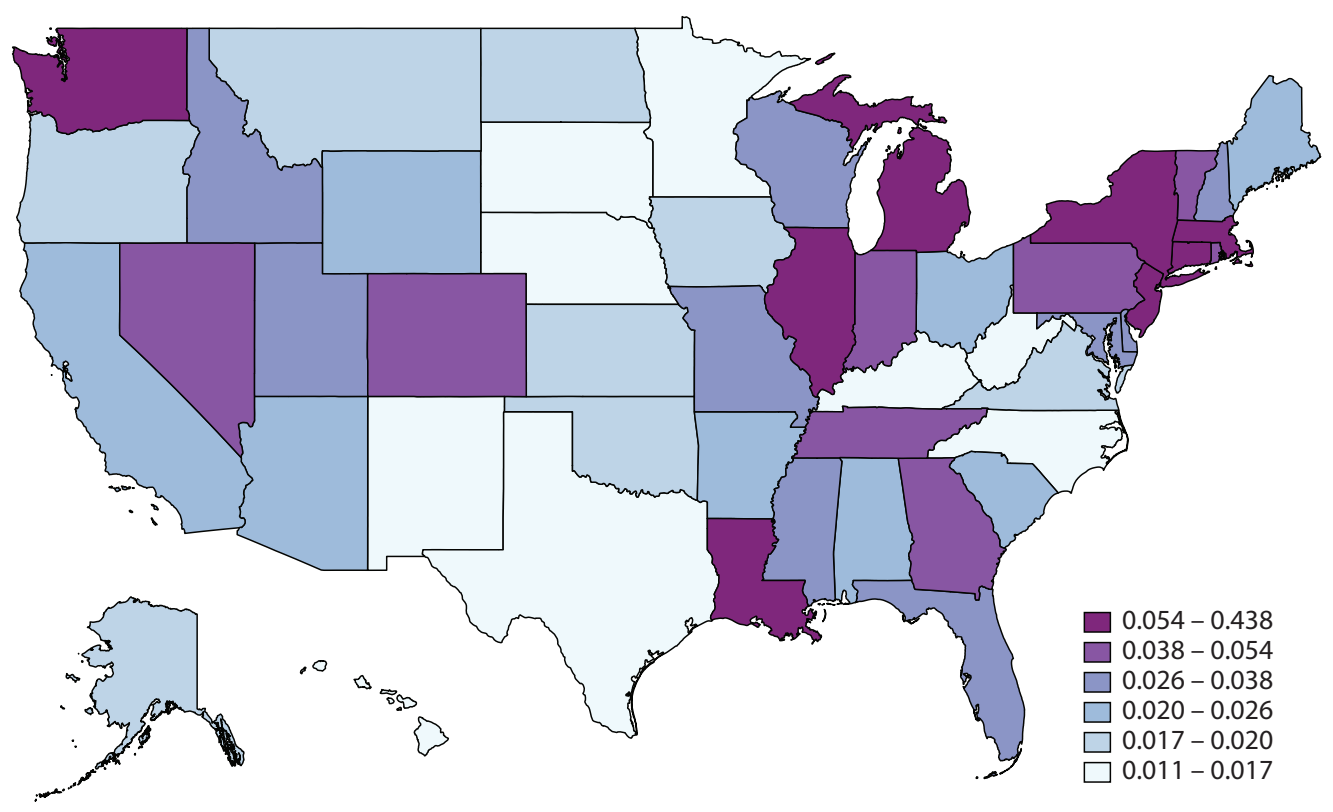

\section{B. Percentages of Workers in High-Risk Occupations}

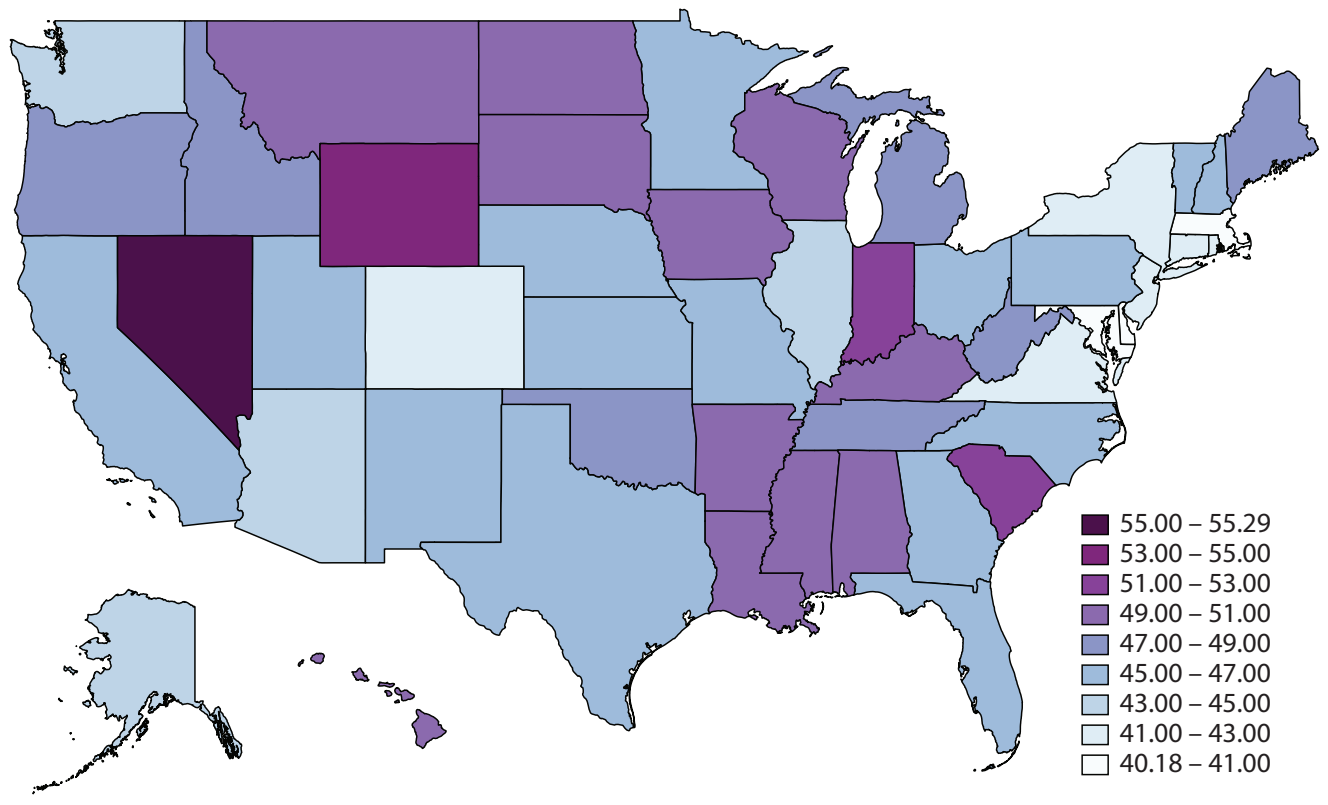

SOURCE: Johns Hopkins University, Current Population Survey, and BLS Occupational Employment Statistics.

correlation is negative $(-0.344) .{ }^{1}$ That is, states with relatively more high-risk workers generally have had a smaller fraction of their population test positive for COVID-19so far. This is probably because viruses such as COVID-19 spread more quickly in densely populated areas such as cities, whose workforces are typically more likely to be essential, salaried, or able to work from home.

We next look at how the percentage of workers who can work from home covaries with the percentage of confirmed COVID-19 cases. Compared with people working 
Figure 2

\section{A. State-Level Percentages of Confirmed COVID-19 Cases and High-Risk Workers}

Percentage of population tested positive for COVID-19

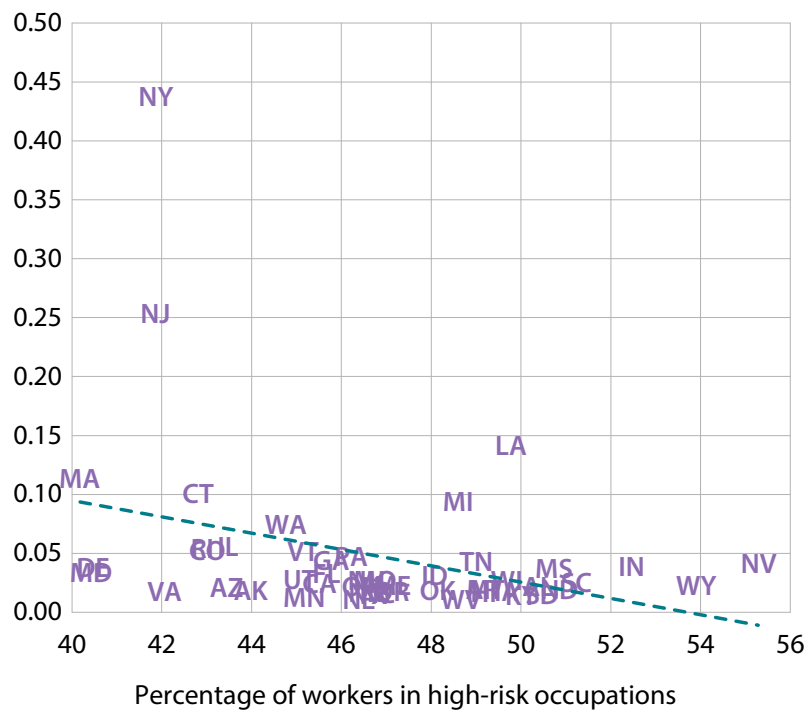

\section{B. State-Level Percentages of Confirmed COVID-19 Cases and Work-from-Home Occupations}

Percentage of population tested positive for COVID-19

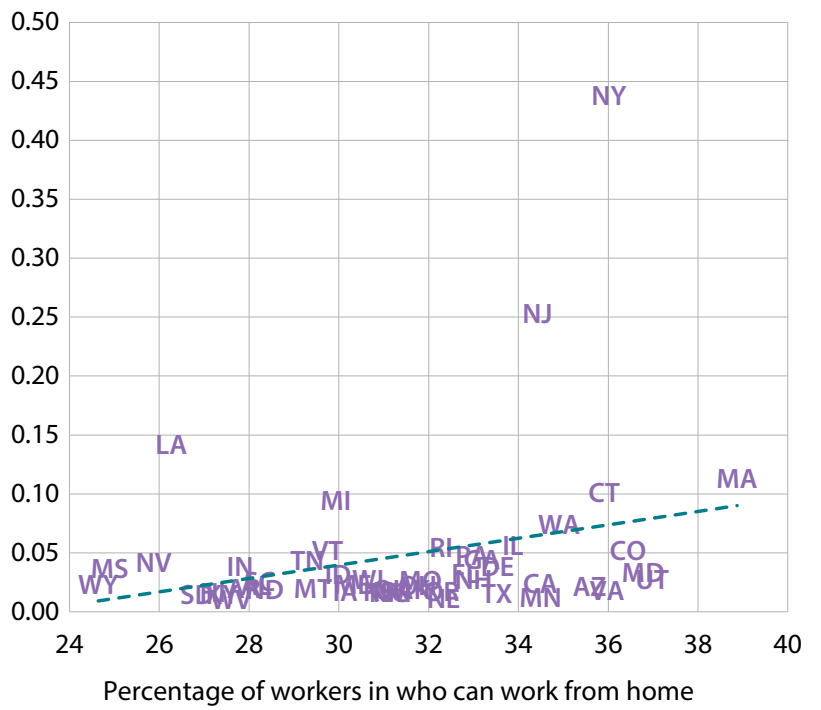

SOURCE: Johns Hopkins University, Current Population Survey, and BLS Occupational Employment Statistics.

on-site in essential occupations, these workers are less exposed to the virus; compared with those who are simply salaried, they can continue to work. Panel B of Figure 2 plots the percentage of workers who can work from home against the percentage of the infected population. The variables are positively correlated $\left(0.280,{ }^{2}\right.$ which is consistent with our theory: States hit harder by the outbreak actually have more workers who, based on their occupations, we assume can work from home). ${ }^{3}$

In conclusion, workers in states currently relatively more severely affected by COVID-19 are more likely to be essential workers, salaried, or able to work from home, mitigating the rise in unemployment in these states. However, our estimates are suggestive at best: These relationships may break down as COVID-19 continues to spread. Further analysis will be needed as the situation continues to evolve.

\begin{abstract}
Notes
${ }^{1}$ The correlation remains negative $(-0.224)$ even after dropping the potential outliers of New Jersey and New York.

2 It is also positive (0.175) after dropping New Jersey and New York.

${ }^{3}$ Given the sporadic nature of COVID-19 testing so far, it is possible that our case numbers reflect local differences in testing more so than genuine differences in the spread of COVID-19. As a robustness check, we re-run our correlation analysis using the fraction of the population in a given state recorded to have died from COVID-19 since these numbers are likely less affected by local testing differences. Our results are qualitatively the same with and without New Jersey and New York.
\end{abstract}

\section{Reference}

Gascon, Charles. "COVID-19: Which Workers Face the Highest Unemployment Risk?" Federal Reserve Bank of St. Louis On the Economy Blog, March 23, 2020; https://www.stlouisfed.org/on-the-economy/2020/march/covid-19-workers-highest-unemployment-risk. 